\title{
GIS ANALYSIS OF SUBSIDIARY STRUCTURES WITHIN A MAJOR NORMAL FAULT TRANSFER ZONE
}

MADISON WOODLEY, Mount Holyoke College

Research Advisor: Michelle Markley

\section{ABSTRACT}

This study focuses on fractures in the transition zone between the Basin and Range province and the Colorado Plateau. These fractures are in the segmented Sevier normal fault transfer zone near Orderville, Utah. This study incorporates ArcGIS to analyze mapped fractures using their orientations on a scanline in the exposed Jurassic Navajo sandstone for two localities: Red Hollow Canyon and Elkheart Cliffs. The Red Hollow Canyon and Elkheart Cliffs are in the steeply west-dipping Sevier fault zone. The first locality, at Red Hollow Canyon, is within a transfer zone between fault segments, where multiple faults and a relay ramp accommodate extension. The second locality, at Elkheart Cliffs, exposes deformation associated with a simple fault geometry, where the single fault accommodates for extension. The Red Hollow Canyon locality has two sets of fractures with different orientations in contrast to a single fracture set in the Elkheart Cliffs. The multiple faults in the Red Hollow Canyon locality caused substantial strain to the Navajo sandstone, which resulted in a higher rate of clustering for all fractures.

\section{INTRODUCTION}

The Sevier Fault is a segmented, steeply west-dipping normal fault system in the Basin and Range province (Davis, 1999; Lund et al., 2008). The fault zone extends for over $300 \mathrm{~km}$, from northern Arizona to southern Utah (Reber et al., 2001). Since the Miocene, the Sevier Fault has accommodated for extension in the transition zone in southern Utah that lies between the Basin and Range province and the Colorado Plateau. The main study area in southern Utah is at the
Orderville geometric bend: a complex region of the Sevier fault zone characterized by different transfer zone geometries (Reber et al., 2001; Lund et al., 2008). The studied fractures in the Sevier fault zone are within the well-researched lithology of the exposed Jurassic Navajo sandstone (Schiefelbein, 2002; Simoneau et al., 2016).

The Sevier Fault near Orderville, Utah is a complex part of the fault zone, with relay ramps and multiple normal faults that accommodate significant displacement in the Red Hollow Canyon (Schiefelbein, 2002; Simoneau et al., 2016). The Red Hollow Canyon has two, possibly three, fault segments (Doelling, 2008) that intersect the mapped fracture network for this study. In the second locality, Elkheart Cliffs, the fault zone is less complicated and has only one fault that is to the western edge of the cliffs. This study's data shows that the stress fields and strain in the Navajo sandstone for each locality affected the relative orientations of fractures and their clustering.

\section{METHODS}

I built the primary ArcGIS map used in this study from orthorectified imagery (captured in 2011, 2014, and 2016), a 10-m resolution DEM for the region, and outlines of major geological features in the region compiled during a previous study (Simoneau et al., 2016). We exported spatial field data, including field observations and sample locations, from a handheld GPS unit and imported this information into ArcGIS. I added geologic map data from Schiefelbein (2002) to show rock units and major faults exposed in the area. I imported the map data and georeferenced it by matching contour lines in the plates to the contour 
lines of the base topographic map I created in ArcGIS.

I merged the four individual DEMs into a single, simplified GIS layer. I created contour lines spaced 20 feet apart for this study by converting the lowest elevation value, 1492.61 meters, to feet and adding a $\mathrm{z}$ factor. The $\mathrm{z}$ factor changed all DEM values from meters to feet for the entire region.

I drew the major faults in ArcGIS using Schiefelbein's (2002) plates to create a separate Faults layer. I replaced the original orthorectified imagery with Google Earth imagery because of the higher resolution in the Google Earth images. To use the imagery from Google Earth Pro (Google Earth, 2018), I panned to select an area, exported and saved the image, added the image to ArcGIS, and then georeferenced it. I georeferenced each Google Earth by matching a minimum of three points from the base orthorectified images to verify the dimensions, latitude, and longitude for each imported image.

I created an ArcGIS layer to build a fracture dataset in which I drew lines on top of visible fractures in the Navajo sandstone. ArcGIS calculated the fracture orientations by adding a geometrical attribute called "Bearing" to each fracture. I quantified the interfracturing spacing with the Measure tool for the distances between each fracture along a specific scanline. The scanline is a projected horizontal line used to quantify discontinuities in rock units.

I excluded one region from my study. In Red Hollow Canyon, the canyon narrows and visibly warps any potential mapped fractures in the Google Earth images. This is likely due to the shading and extreme topographic relief in the canyon that is in the eastern part of Red Hollow Canyon.

\section{EQUATIONS}

In order to quantify fracture spacing and intensity, I created scanlines in ArcGIS by drawing lines perpendicular to fracture sets in a rock unit (Fig. 1C). The scanlines start from the first fracture in a scanline and end with the last fracture in the scanline. I calculated the fracture intensity by dividing the number of fractures by the length of the scanline. The units for fracture intensity are fractures per meter.

Fracture intensity (1) = \# of fractures / scanline length (m)

The average spacing between these fractures is the inverse of equation 3 , or the length of the scanline divided by the number of fractures. The units for the average spacing between fractures are $\mathrm{m} /$ fracture.

Average spacing $(2)=$ scanline length $(m) / \#$ of fractures

The relative clustering of fractures for each scanline is the coefficient of variation, $\mathrm{Cv}$. The $\mathrm{Cv}$ is the standard deviation of the inter-fracture spacing population divided by the mean of the same population of fractures (Kagan and Jackson, 1991; Gillespie et al., 1999; Supak et al., 2006; Hooker et al., 2013). The relative clustering, $\mathrm{Cv}$, is unitless.

$C_{v}(3)=$ standard deviation of spacing / mean of spacing

If $\mathrm{C}_{\mathrm{v}}$ equals 0 , the inter-fracture spacing is considered regular and evenly spaced. If the $\mathrm{Cv}$ is equivalent to 1 , the fractures are randomly spaced and considered more clustered. For $\mathrm{Cv}$ values greater than 1, the data reflects more clustering (Gillespie et al., 1999).

\section{RESULTS}

\section{Red Hollow Canyon Scanlines}

The fracture network for the first locality, Red Hollow Canyon, consists of two sets of fractures on 13 scanlines. The 13 scanlines are sub-divided into two regions: RHC-1 and RHC-2. These two regions each represent a single set of fractures that show different orientations across a major transfer zone in the Red Hollow Canyon. The first fracture set, RHC1 , is within the transfer zone between several fault segments in the locality. The other region, RHC-2, has fractures that lie in the footwall of the eastern-most fault in the major transfer zone.

The first region, RHC-1, in the Red Hollow Canyon has three locations: RHC_WT, RHC_MID, and RHC NF1 (Table 1). The first two locations in this region trend NNE. These fractures have orientations that range from $23.6^{\circ}$ to $30.1^{\circ}$. The third location in this region has a more northerly trend with a lower mean 

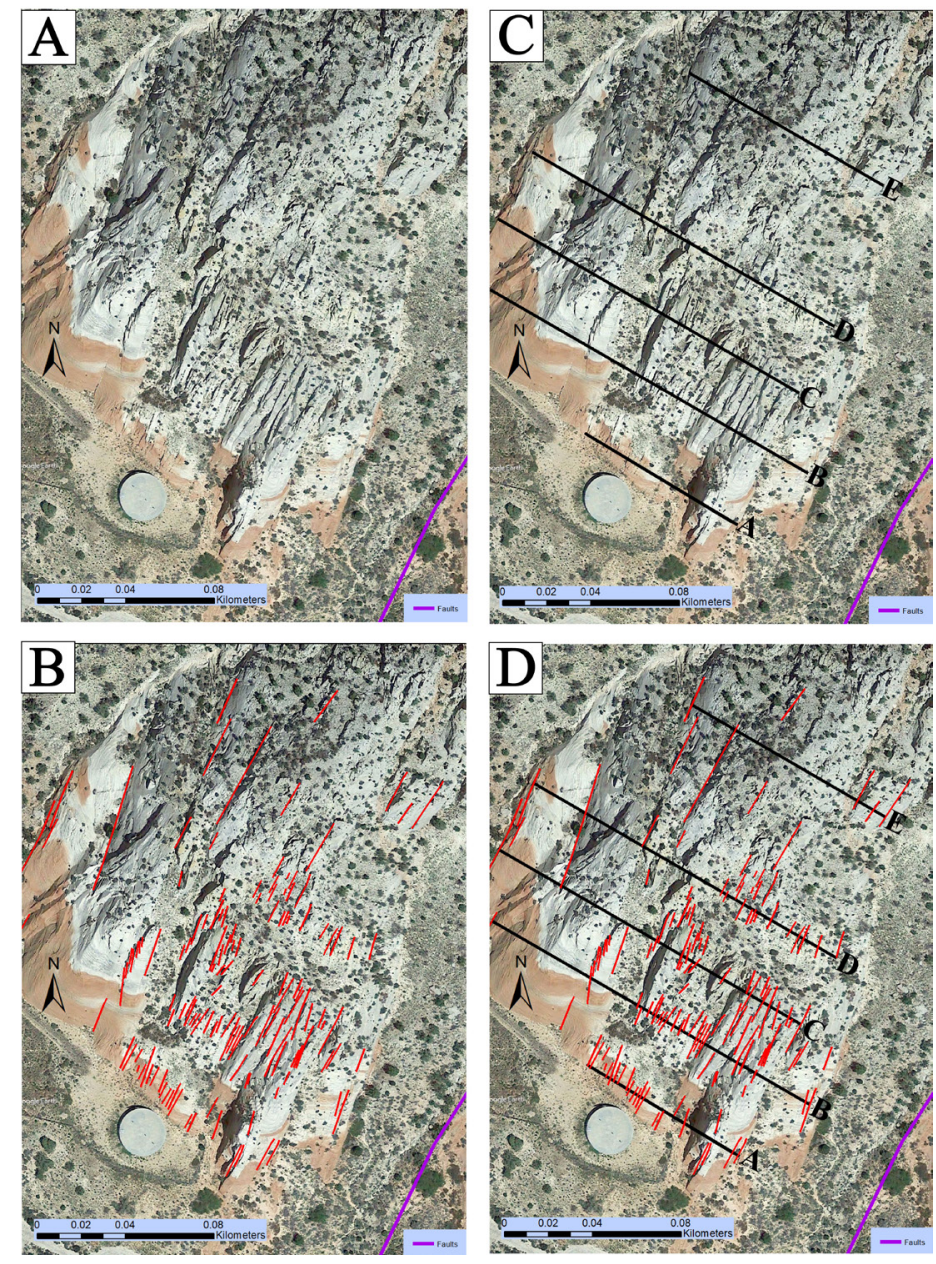

Fig. 1: Sequence of fracture mapping for the Red Hollow Canyon locality. The Red Hollow Canyon is located in southern Utah, outside the town of Orderville, Utah. This part of the locality is between multiple faults segments in a transfer zone. (A) Google Earth image of visible fractures in exposed rock at the western edge of the major transfer zone in Red Hollow Canyon. (B) Lines representing visible fractures in the exposed rock are shown in red. The purple line represents a fault segment. (C) The horizontal and parallel scanlines in black are perpendicular to the fracture network. The scanlines pictured are scanlines $A$ to $E$ in Table 1 (i.e. the RHC_WT lines). The scanlines start with RHC_WT1 at the base of the rock face and end with RHC_WT5 at the northernmost scanline. (D) The previous figures are layered into one image to show the scanlines with the mapped fractures.

\section{bearing of $15.1^{\circ}$.}

The second region, RHC-2, in the Red Hollow Canyon has only location, RHC_LD, compared to the three locations in RHC-1. The fractures in this region have RHC_LD in the beginning of their name in Table 1. RHC-2 has a second set of fractures that trend ENE with steeper orientations. These fractures trend ENE with a range of orientations from $54.1^{\circ}$ to $61.3^{\circ}$.

These two sets of fractures are combined in a separate attribute called RHC-ALL. RHC-ALL combines the two regions, $\mathrm{RHC}-1$ and $\mathrm{RHC}-2$, in Table 3 for side-by-side comparison to the Elkheart Cliffs data (ELHEART). The RHC-ALL and ELKHEART data do not show a significant relationship with fracture intensity.

\section{Elkheart Cliffs Scanlines}

The second locality, Elkheart Cliffs, has a single set of fractures on nine scanlines. The Elkheart Cliffs fractures are in an area with a simpler geometry than Red Hollow Canyon. These fractures are near a single fault segment versus a major transfer zone with multiple fault segments. The spacing between the fractures in the Elkheart Cliffs is smaller than the spacing in Red Hollow Canyon. This locality has orientations similar to the first region, RHC-1, in the Red Hollow Canyon data.

The Elkheart Cliffs data are separated into three locations: ELK_NS, ELK_MS, and ELK_SS. Each of these locations trend NNE and have fractures with a mean bearing similar to the RHC-1. The Elkheart Cliffs fractures show a larger range of orientations across all three locations than both regions in the Red Hollow Canyon. The orientations in the three locations in the Elkheart Cliffs ranges from $17.8^{\circ}$ to $29.2^{\circ}$.
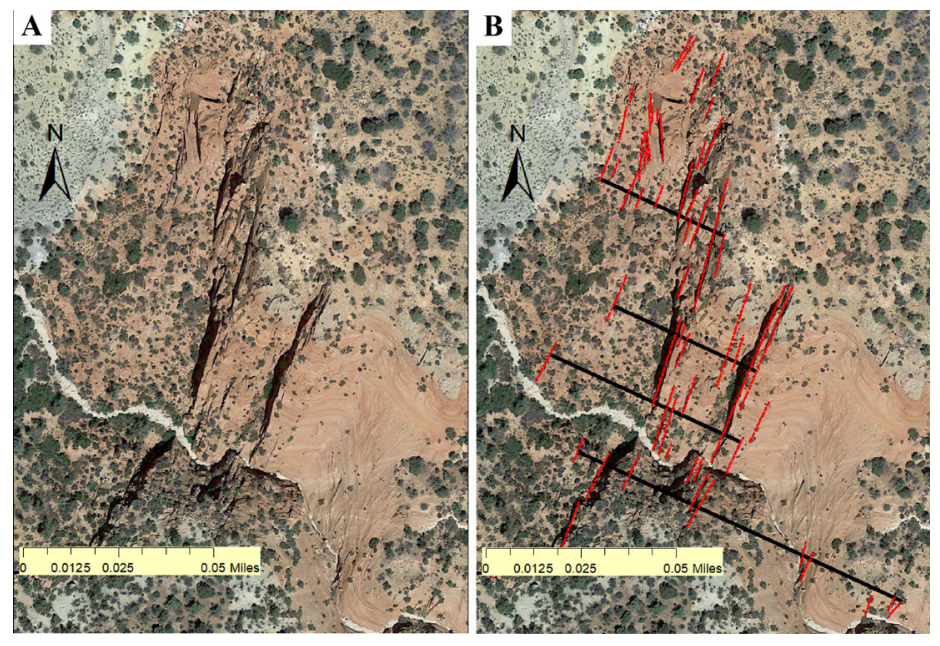

Fig. 2: The fracture mapping for the northernmost location, ELK NS, of the Elkheart Cliffs data. (A) The exposed rock units visible with Google Earth Imagery without any mapped fractures. (B) The mapped fractures in red are perpendicular to the parallel scanlines in black. These scanlines include scanlines $N$ to $Q$ in Table 1 (i.e. the ELK_NS lines). The scanlines start with ELK_NS1 south of the white footpath and end with ELK_NS4 at the northernmost scanline. 
Table 1: Raw Data of Fracture Mapping Grouped by Study Area

\begin{tabular}{|c|c|c|c|c|c|c|}
\hline SCANLINE & LOCATION & $\begin{array}{c}\text { MEAN } \\
\text { BEARING (') }\end{array}$ & LENGTH (m) & $\begin{array}{c}\text { \# OF } \\
\text { FRACTURES }\end{array}$ & $\begin{array}{c}\text { FRACTURE } \\
\text { INTENSITY } \\
\text { (fracture/m) }\end{array}$ & $\begin{array}{c}\text { MEAN } \\
\text { SPACING } \\
\text { (m/fracture) }\end{array}$ \\
\hline A & RHC_WT1 & 25.3 & 80.2 & 16 & 0.200 & 5.0 \\
\hline B & RHC_WT2 & 24.3 & 166.8 & 23 & 0.138 & 7.3 \\
\hline C & RHC_WT3 & 23.6 & 158.0 & 16 & 0.101 & 9.9 \\
\hline D & RHC_WT4 & 24.0 & 158.6 & 15 & 0.095 & 10.6 \\
\hline E & RHC_WT5 & 30.1 & 102.1 & 5 & 0.049 & 20.4 \\
\hline F & RHC_MID1 & 32.2 & 36.2 & 3 & 0.083 & 12.1 \\
\hline G & RHC_MID2 & 25.0 & 67.7 & 4 & 0.059 & 16.9 \\
\hline H & RHC_NF1 & 15.1 & 13.2 & 4 & 0.303 & 3.3 \\
\hline I & RHC_LD1 & 61.3 & 255.4 & 25 & 0.098 & 10.2 \\
\hline J & RHC_LD2 & 60.8 & 188.3 & 17 & 0.090 & 11.1 \\
\hline K & RHC_LD3 & 54.1 & 102.4 & 13 & 0.127 & 7.9 \\
\hline L & RHC_LD4 & 59.5 & 108.3 & 9 & 0.083 & 12.0 \\
\hline M & RHC_LD5 & 55.0 & 92.5 & 7 & 0.076 & 13.2 \\
\hline N & ELK_NS1 & 26.0 & 151.2 & 9 & 0.060 & 16.8 \\
\hline O & ELK_NS2 & 21.5 & 88.8 & 6 & 0.068 & 14.8 \\
\hline P & ELK_NS3 & 20.5 & 67.3 & 8 & 0.119 & 8.4 \\
\hline Q & ELK_NS4 & 19.0 & 57.7 & 10 & 0.173 & 5.8 \\
\hline R & ELK_MS1 & 17.8 & 190.9 & 6 & 0.031 & 31.8 \\
\hline S & ELK_MS2 & 29.2 & 24.2 & 4 & 0.165 & 6.1 \\
\hline T & ELK_MS3 & 27.5 & 42.4 & 3 & 0.071 & 14.1 \\
\hline U & ELK_MS4 & 22.9 & 47.5 & 7 & 0.147 & 6.8 \\
\hline V & ELK_SS1 & 19.6 & 25.2 & 6 & 0.238 & 4.2 \\
\hline & & & & & & \\
\hline
\end{tabular}

\section{Clustering}

The calculated $\mathrm{Cv}$ for the Red Hollow Canyon locality is 1.2-1.3 for both fracture sets (Table 2). These values indicate a clustered and randomly spaced fracture network. The Elkheart Cliffs has a smaller Cv of 0.8 (Table 2). These fractures are more evenly spaced and less random than the Red Hollow Canyon fractures.

The scanline data and clustering of the fractures indicates that there are two sets of fractures for the Red Hollow Canyon locality with two different orientations. The first set of fractures in Red Hollow Canyon (RHC-1) are NNE, with azimuths close to 25 degrees. The second set of fractures (RHC-2) are ENE, with azimuths around 55 degrees. The fractures in Elkheart Cliffs are also NNE and have similar orientations to RHC-1. The fractures in Red Hollow Canyon show higher clustering than the more regular Elkheart Cliffs fractures.

\section{DISCUSSION}

The two fracture sets, RHC-1 and ELKHEART, have similar orientations, which suggests they formed at a similar time in the same stress field. The third fracture set, RHC-2, has a different trend and orientation so these fractures are from a second stress field in the Red Hollow Canyon. The complex system of multiple faults in the Red Hollow Canyon caused more strain on the Navajo sandstone rock unit. This increased strain in the rock increased the clustering in the Red
Hollow Canyon locality.

The variations in the fracture clustering between the two localities is likely related to fault zone dynamics. At Elkheart Cliffs, the Sevier fault zone has only one fault segment, and fracture clustering is relatively low. At Red Hollow Canyon, there are at least two significant normal faults that bookend a transfer zone, which resulted in a relatively higher amount of clustering. The rates of clustering in the Red Hollow Canyon are consistent for both regions: RHC-1 and RHC-2. The transfer zone with multiple faults and the higher strain on the Navajo sandstone in Red Hollow Canyon increased the clustering of fractures.

\section{ACKNOWLEDGMENTS}

This material is based upon work supported by the Keck Geology Consortium and the National Science Foundation under Grant No. 1659322. Thank you to Ben Surpless for his guidance in the field and with the subsequent analysis I completed during the following year. I also want to thank Michelle Markley for her support and critiques to help me write this contribution.

Table 2: Coefficient of Variation, $C_{v}$, by Scanline and Region

\begin{tabular}{|c|c|c|c|c|}
\hline SCANLINE & LOCATION & Cv & REGION & MEDIAN Cv \\
\hline A & RHC_WT1 & 1.3 & RHC-1 & 1.3 \\
\hline B & RHC_WT2 & 1.7 & RHC-2 & 1.2 \\
\hline C & RHC_WT3 & 1.3 & RHC_ALL & 1.3 \\
\hline D & RHC_WT4 & 1.2 & ELKHEART & 0.8 \\
\hline$E$ & RHC_WT5 & 1.3 & & \\
\hline $\mathrm{F}$ & RHC_MID1 & 0.9 & & \\
\hline G & RHC_MID2 & 1.5 & & \\
\hline $\mathrm{H}$ & RHC_NF1 & 0.7 & & \\
\hline 1 & RHC_LD1 & 0.8 & & \\
\hline J & RHC_LD2 & 1.4 & & \\
\hline $\mathrm{K}$ & RHC_LD3 & 1.2 & & \\
\hline L & RHC_LD4 & 1.6 & & \\
\hline$M$ & RHC_LD5 & 1.1 & & \\
\hline $\mathrm{N}$ & ELK_NS1 & 1.1 & & \\
\hline 0 & ELK_NS2 & 1.2 & & \\
\hline$P$ & ELK_NS3 & 1.2 & & \\
\hline$Q$ & ELK_NS4 & 0.7 & & \\
\hline$R$ & ELK_MS1 & 1.4 & & \\
\hline $\mathrm{S}$ & ELK_MS2 & 0.7 & & \\
\hline$T$ & ELK_MS3 & 0.7 & & \\
\hline$U$ & ELK_MS4 & 0.8 & & \\
\hline V & ELK_SS1 & 0.7 & & \\
\hline
\end{tabular}


Table 3: Summary of Fracture Mapping Data

\begin{tabular}{|c|c|c|c|c|}
\hline REGION & MEDIAN BEARING $\left(^{\circ}\right)$ & $\begin{array}{c}\text { \# OF FRAC- } \\
\text { TURES }\end{array}$ & $\begin{array}{c}\text { MEDIAN FRACTURE INTEN- } \\
\text { SITY (fracture/m) }\end{array}$ & $\begin{array}{c}\text { MEDIAN SPACING } \\
\text { (m/fracture) }\end{array}$ \\
\hline RHC-1 & 24.7 & 86 & 0.098 & 10.2 \\
\hline RHC-2 & 59.5 & 71 & 0.090 & 11.1 \\
\hline RHC_ALL & 30.1 & 157 & 0.095 & 10.6 \\
\hline ELKHEART & 21.5 & 59 & 0.119 & 8.4 \\
\hline
\end{tabular}

\section{REFERENCES}

Davis, George Herbert. Structural geology of the Colorado Plateau region of southern Utah, with special emphasis on deformation bands. Vol. 342 . Geological Society of America, 1999.

Doelling, H. H. 'Geologic map of the Kanab 30'x 60'quadrangle." Kane and Washington counties, Utah, and Coconino and Mohave counties, Arizona: Utah Geological Survey Miscellaneous Publications (2008).

Google Earth 9.2.72.0. 2018. Red Hollow Canyon $37^{\circ} 16^{\prime} 15^{\prime} \mathrm{N}, 112^{\circ} 37^{\prime} 38^{\prime \prime} \mathrm{W}$, elevation $\sim 1700 \mathrm{~m}$. 3D map, Satellite layer, viewed July 8th - 15th 2018. <http://www.google.com/earth/index.html>

Gillespie, P. A., J. J. Walsh, J. Watterson, C. G. Bonson, and T. Manzocchi. "Scaling relationships of joint and vein arrays from The Burren, Co. Clare, Ireland." Journal of Structural Geology 23, no. 2-3 (2001): 183-201.

Hooker, J. N., S. E. Laubach, and R. Marrett. "Fracture-aperture size-Frequency, spatial distribution, and growth processes in stratabounded and non-strata-bounded fractures, Cambrian Mesón Group, NW Argentina.” Journal of Structural Geology 54 (2013): 54-71.

Kagan, Yan Y., and David D. Jackson. "Long-term earthquake clustering." Geophysical Journal International 104, no. 1 (1991): 117-133.

Lund, W. R., T. R. Knudsen, and G. S. Vice. "Paleoseismic reconnaissance of the Sevier fault." Kane and Garfield Counties, Utah: Utah Geological Survey Special Study 122 (2008): 31.
Reber, Spence, Wanda J. Taylor, Meg Stewart, and Ilsa M. Schiefelbein. "Linkage and reactivation along the northern Hurricane and Sevier faults, southwestern Utah." (2001): 379-400.

Schiefelbein, I. "Fault segmentation, fault linkage, and hazards along the Sevier fault, southwestern Utah [MS thesis]: Las Vegas." University of Nevada at Las Vegas (2002).

Simoneau, S., Surpless, B., and Mathy, H., 2016.

"The evolution of subsidiary fracture networks in segmented normal fault systems." GSA National Meeting, Abstracts with Programs, Denver, Colorado (2016).

Supak, S., D. R. Bohnenstiehl, and W. R. Buck. "Flexing is not stretching: An analogue study of flexure-induced fault populations." Earth and Planetary Science Letters 246, no. 1-2 (2006): 125-137. 